\title{
CARACTERÍSTICAS DO COMÉRCIO INFORMAL DE PLANTAS MEDICINAIS NO MUNICÍPIO DE LAGOA NOVA/RN
}

\author{
F. A. G. Rocha², L. S. G. Araújo', T. G. D. Lima', E. R. Silva', P. A. Silva', M. K. M. Gundim', M. F. F. Araújo³, N. D. \\ L. Costa ${ }^{3}$. \\ ${ }^{1,2}$ Instituto Federal de Educação, Ciência e Tecnologia do Rio Grande do Norte. \\ ${ }^{3}$ Universidade Federal do Rio Grande do Norte. \\ E-mail: angelo.gurgel@ifrn.edu.br ${ }^{2}$
}

\section{RESUMO}

O uso de plantas medicinais está presente na cultura de todos os povos, sendo a sua comercialização principalmente realizada em feiras livres. As condições de higiene inadequadas presentes nos pontos de venda, associadas à crença de que "o natural não faz mal", podem resultar em agravos à saúde dos consumidores. Objetivamos caracterizar o perfil socioeconômico dos comerciantes de plantas medicinais do município de Lagoa Nova/RN, descrevendo seus métodos de armazenamento e exposição, bem como suas crenças em relação à segurança no uso de tais recursos terapêuticos. Foram realizadas entrevistas, orientadas por formulário estruturado. Dos entrevistados, 60\% eram negros, $20 \%$ pardos e $40 \%$ brancos; o sexo masculino predominou, com frequência correspondente a $60 \%$ dos casos. A transmissão do conhecimento etnobotânico e do ponto de comercialização eram predominantemente familiar, atingindo percentual de $80 \%$. As condições estruturais e de higiene nos pontos de venda eram precárias. Os entrevistados desconheciam os riscos potenciais à saúde dos usuários presentes no uso inadequado de plantas medicinais.

PALAVRAS-CHAVE: etnobotânica, medicina tradicional, fitoterapia, feiras livres.

\section{CHARACTERISTICS OF INFORMAL TRADE OF MEDICINAL PLANTS IN THE CITY OF LAGOA NOVA/RN}

\section{ABSTRACT}

The use of medicinal plants is present in the culture of all nations, it's commonly trade at the open street markets. The bad conditions showed on the sell places, associated with the belief that "the natural cannot be bad", can result in problems to the health of the consumers. We aimed to characterize the socioeconomic profile of the sellers of herbal medicine from Lagoa Nova/RN, describing their methods of stock and exposure, also their beliefs into the use of these therapeutic resources. Interviews were held oriented by structured forms. From the total of the interviewees, sixty per cent were black, twenty per cent were mixedrace and forty per cent were white. The males predominated with sixty per cent of the interviewees. The transmission of ethno botanical knowledge and the point of sale were mostly familiar, reaching eighty per cent. The structure conditions and the hygiene in the point of sale were precarious. The interviewees did not know about the potential risks to the health to the consumers in the inappropriate use of the herbal medicine.

KEYWORDS: Ethnobotany, traditional medicine, phytotherapy, street fair. 


\section{CARACTERÍSTICAS DO COMÉRCIO INFORMAL DE PLANTAS MEDICINAIS NO MUNICÍPIO DE LAGOA NOVA/RN.}

\section{INTRODUÇÃO}

Ao longo de sua história, as comunidades humanas têm recorrido ao uso de recursos naturais como fonte para a solução de seus problemas cotidianos. Neste contexto, espécies da fauna e flora locais são empregadas com finalidade terapêuticas, constituindo ao longo do tempo, o que conhecemos como sistemas de Medicina Tradicional.

A utilização de espécies vegetais dotadas de propriedades bioativas é um traço comum a todas as comunidades, sejam elas autóctones ou não. A Organização Mundial da Saúde (OMS) estima que $80 \%$ da população mundial deposita confiança na utilização de plantas medicinais, dependendo destas para a solução de seus problemas de saúde.

Apesar da eficácia terapêutica das plantas medicinais terem sido reconhecidas tanto pela OMS quanto pela indústria farmacêutica, os usuários ainda têm nas feiras livres a fonte principal para a aquisição das espécies que utiliza. Espaços de caráter cíclico, socialmente construídos e acordados, as feiras livres são importantes elementos de integração econômica e cultural entre comunidades distintas. Nestes espaços, contudo, em geral estão presentes a sanitização deficiente, a baixa qualidade do material comercializado e a falta de conhecimento técnico do comerciante acerca da segurança no uso das plantas medicinais que comercializa. Tal conjunção de fatores pode interferir de forma negativa tanto na qualidade quanto na segurança do uso das plantas medicinais, resultando em risco à saúde dos usuários.

\section{FUNDAMENTAÇÃO TEÓRICA}

O Homem sempre obteve da natureza os recursos necessários ao seu abrigo, alimentação e tratamento para as suas dores e males. Ao longo do tempo, observou que o controle na dosagem de extratos ou partes de órgãos de certas espécies vegetais permitia a sua aplicação terapêutica efetiva, ampliando o seu uso para além da alimentação. A observação sistemática das propriedades bioativas de plantas consumidas por humanos e animais e dos efeitos que estas provocavam, teve participação significativa na criação dos sistemas de Medicina Tradicional (LORENZI; MATOS, 2002; SCHOLZ et al, 2002).

Segundo estimativas da Organização Mundial de Saúde (OMS), cerca de $80 \%$ da população mundial confiam no uso de plantas medicinais, sendo que nos países em desenvolvimento, $80 \%$ das pessoas depende deste recurso terapêutico para suprir as suas necessidades básicas de saúde (RODRIGUES; GUEDES, 2006). No Brasil pesquisas demonstram que $91,9 \%$ da população fez uso de alguma planta medicinal, sendo que $46 \%$ mantêm cultivo caseiro de espécies com propriedades terapêuticas (ASSOCIAÇÃO BRASILEIRA DAS EMPRESAS DO SETOR DE FITOTERÁPICOS, 2007). De acordo com MELO et al (2007), existe no Brasil uma farmacopéia popular diversificada, baseada em plantas medicinais, produto direto da miscigenação cultural envolvendo africanos, europeus e indígenas.

O comércio popular de plantas medicinais ocorre predominantemente em feiras livres, espaços públicos voltados à atividade mercantil cíclica. Caracterizadas pela estrutura não permanente e condições de higiene geralmente precárias, tais espaços exercem um relevante 
papel na integração entre comunidades distintas. As feiras livres são eventos socialmente acordados que contribuem de forma positiva para o intercâmbio cultural e para o fluxo de capitais entre as comunidades da região na qual se situam. O papel integrador das feiras livres se revela em maior proporção nos municípios da região Norte e Nordeste do Brasil (ALMEIDA; PENA, 2011; BRASIL, 1998; MINNAERT; FREITAS, 2010; ROCHA, 2007; ROCHA et al., 2010).

A venda de plantas medicinais nas feiras livres também é relevante em aspectos diversos do econômico; a atividade é fundamental na conservação e transmissão do conhecimento tradicional presente nas comunidades e viabiliza o acesso fácil e barato a recursos terapêuticos que podem representar a única opção de tratamento disponível às populações carentes. Contudo, devemos considerar os riscos advindos do uso incorreto das espécies vegetais ou decorrentes da sua baixa qualidade. De modo geral, as deficiências na estrutura física, logística e condições precárias presentes nas feiras livres, são fatores capazes de interferir na qualidade, eficácia e segurança no uso do recurso terapêutico em questão. (MINNAERT; FREITAS, 2010; FERREIRA, 2002; ROCHA, 2007; ROCHA et al., 2010; WORLD HEALTH ORGANIZATION, 2007).

A crença de que "o que é natural não faz mal", associada à revalorização dos recursos terapêuticos tradicionais pela grande mídia, pode levar ao uso descontextualizado destas práticas. Tal como as drogas sintéticas, os efeitos farmacológicos atribuídos a uma dada espécie vegetal advém da presença de uma ou mais substâncias biologicamente ativas. Contudo, diferentemente das drogas alopáticas, os fitoquímicos estão presentes em concentrações variáveis e associados a centenas de outras substâncias resultantes do metabolismo primário ou secundário da planta. Sendo assim, o uso de plantas medicinais deve ser cuidadoso, considerando os riscos potenciais de intoxicações, interações indesejadas resultantes do uso contemporâneo com medicamentos sintéticos ou com outras plantas medicinais (CAPASSO et al., 2000; ROCHA, 2009).

\section{OBJETIVOS}

O presente estudo objetivou caracterizar o perfil socioeconômico dos comerciantes de plantas medicinais do município de Lagoa Nova/RN, descrevendo seus métodos de armazenamento e exposição, bem como suas crenças em relação à segurança no uso de tais recursos terapêuticos.

\section{MATERIAL E MÉTODOS}

Trata-se de um estudo observacional (não experimental), descritivo, de caráter longitudinal, no qual foram observadas e descritas as características socioeconômicas, culturais e higiênico-sanitárias presentes na comercialização informal de plantas medicinais na feira livre do município estudado.

\section{- Área de estudo}


O presente estudo foi desenvolvido em uma região do semiárido brasileiro, estado do Rio Grande do Norte, mesorregião Central Potiguar, microrregião Serra de Santana, município de Lagoa Nova, $\left(06^{\circ} 05^{\prime} 45,6^{\prime \prime}\right.$ de latitude sul e $36^{\circ} 28^{\prime} 08,4^{\prime \prime}$ de longitude oeste) conforme a Figura 1 (BRASIL, 2005). A área selecionada para as observações situa-se na zona urbana do município, correspondendo à sua feira livre.

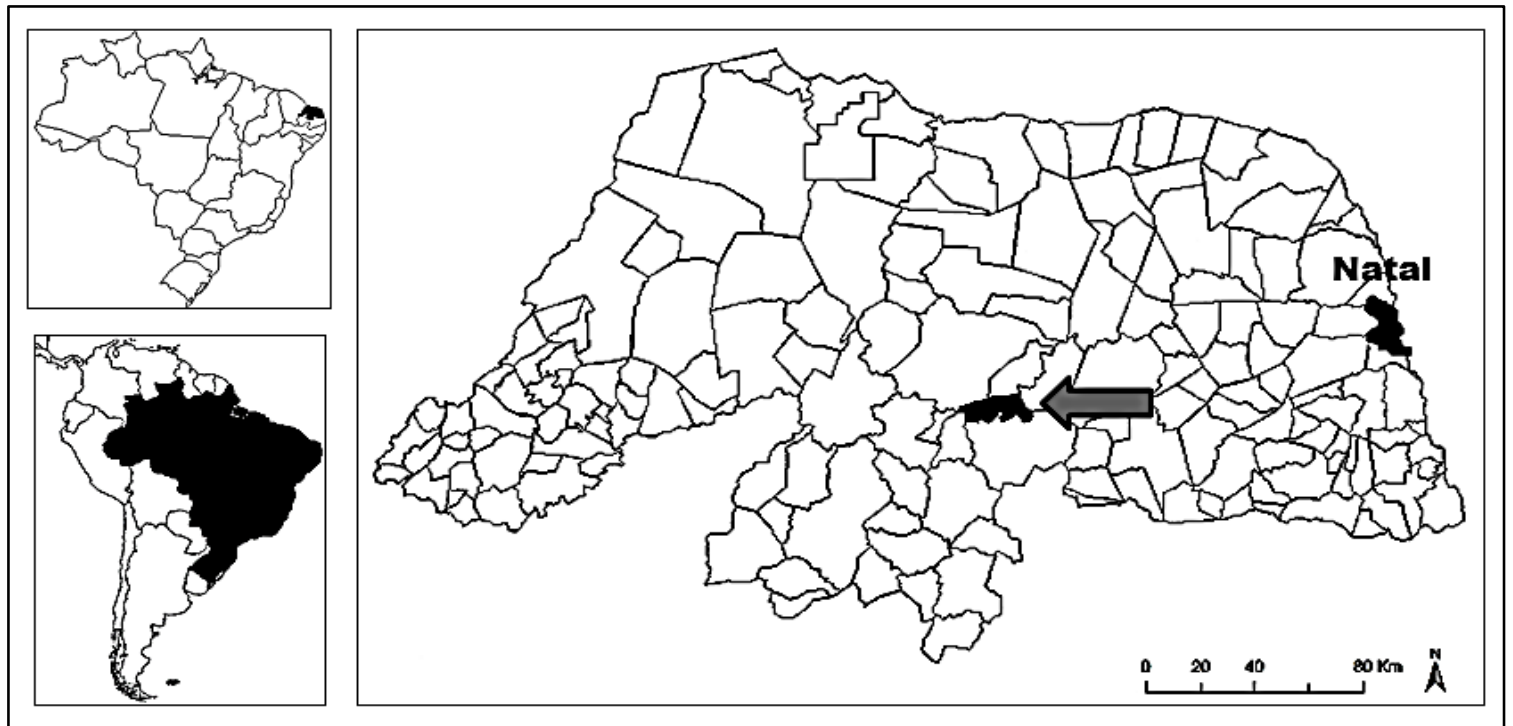

FONTE: adaptado a partir das fontes cartográficas do IBGE (INSTITUTO BRASILEIRO DE GEOGRAFIA E ESTATÍSTICA, 2013b).

Figura 1 - Localização geográfica do município de Lagoa Nova (indicado pela seta) e sua posição relativa à capital do estado, Natal.

\section{- População e amostra.}

\section{Seleção Amostral dos pontos de comercialização a serem estudados.}

Ao longo do mês de maio de 2012, foram realizadas visitas in loco a feira livre de Lagoa Nova, nos dias de maior movimentação de clientes e mercadorias. Tal procedimento objetivou a identificação de todos os pontos de comercialização de plantas medicinais e seus derivados presentes na área estudada. Por ocasião da visita, verificou-se qual o horário mais adequado para a realização do contato com os responsáveis, de forma a gerar o mínimo de interferência em sua atividade comercial. Adicionalmente, verificou-se a assiduidade da participação dos comerciantes na feira livre estudada.

Para a seleção dos participantes empregou-se amostragem não probabilística, tendo em vista o reduzido número de elementos constituintes do universo estudado. Desse modo, foi abrangido no presente estudo o maior número possível de feirantes. Adotou-se como critérios de inclusão praticar de forma contínua a comercialização de plantas medicinais (isoladamente ou em conjunto com outros produtos) e participar assiduamente da feira livre, estando nela estabelecido ao menos há um ano. Como critérios de exclusão foram adotados a não comercialização de plantas medicinais, comercialização de forma esporádica e exercer a atividade na feira de forma descontínua há menos de um ano.

\section{- Coleta de Dados.}


A coleta dos dados ocorreu em duas semanas consecutivas, na segunda quinzena do mês de maio de 2012. Os participantes foram entrevistados em seu próprio ponto de comercialização, no horário de menor movimento de clientes, de modo a evitar interferências excessivas em sua atividade comercial. Para coleta e registro das informações, utilizou-se questionário estruturado, composto por 22 questões de múltipla escolha, relacionadas ao perfil socioeconômico dos entrevistados e à caracterização das práticas de comercialização e crenças pessoais acerca do comércio e uso de plantas medicinais.

Todos os dados obtidos em campo foram armazenados e processados com uso do Software Statistica ${ }^{\circledR}$ (STATSOFT, 2010). Para o registro e análises dos dados financeiros obtidos, considerou-se o valor do Salário Mínimo Nominal vigente no período compreendido entre janeiro e dezembro de 2012, correspondente a $\mathrm{R} \$ \mathbf{6 2 2 , 0 0}$ (BRASIL, 2011). Tendo em vista o número reduzido de comerciantes de plantas medicinais atuantes na área estudada, foram utilizadas ferramentas descritivas para a análise e expressão dos resultados.

\section{RESULTADOS E DISCUSSÃO}

Na feira livre de Lagoa Nova/RN, registrou-se a presença de seis comerciantes de plantas medicinais, sendo que um deles recusou-se a participar do estudo.

A análise das observações in loco nos permitiu verificar que o comércio de plantas medicinais na área estudada é predominantemente uma atividade exercida pelos homens, que compõem $60,0 \%$ do total observado (Figura 2).

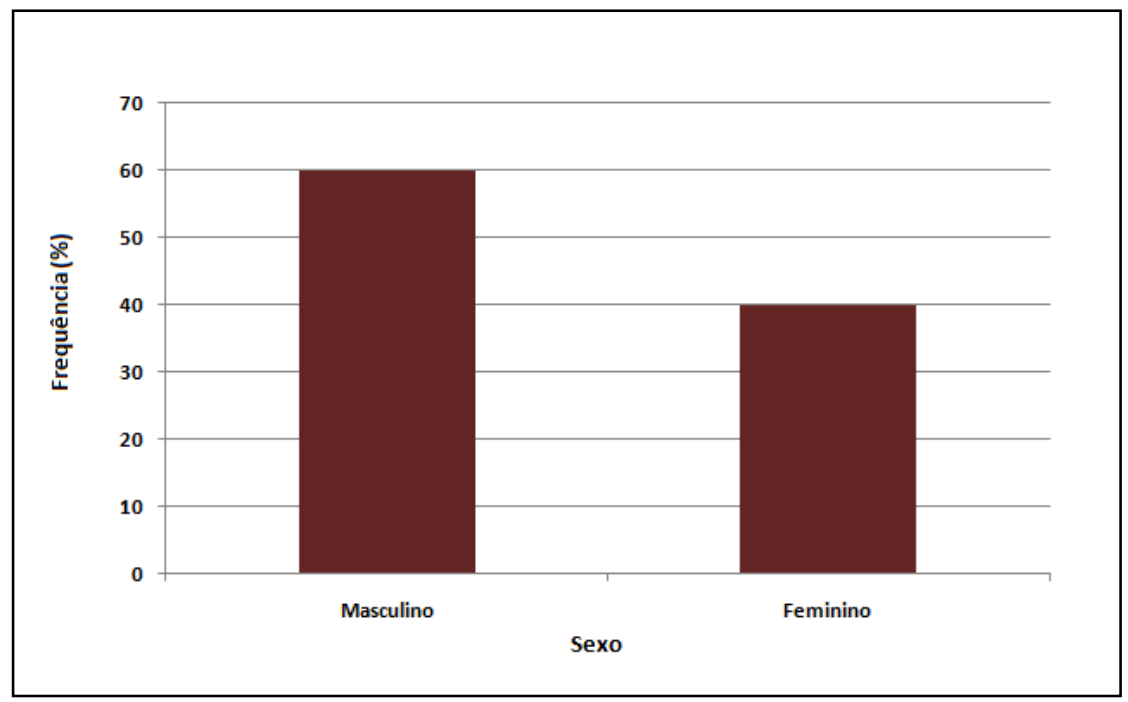

FONTE: Dados do pesquisador.

Figura 2 - Distribuição percentual dos comerciantes de plantas medicinais atuantes na feira livre de Lagoa Nova/RN segundo o seu sexo.

Nossas observações são concordantes com os relatos de Alves, Silva e Alves (2008) que descreveram a predominância masculina na comercialização informal de plantas medicinais nas cidades de São Luiz/MA, Belém/PA e Teresina/PI, fato também constatado por Rocha et al. (2010) em Passo Fundo/RS. 


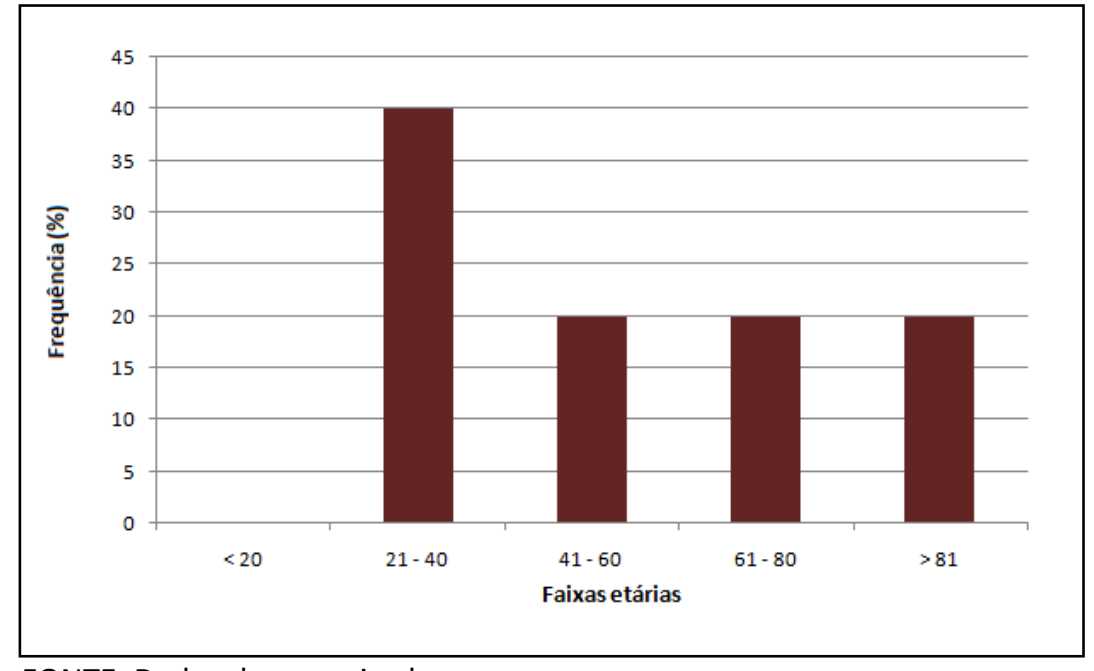

FONTE: Dados do pesquisador

Figura 3 - Distribuição percentual dos comerciantes de plantas medicinais atuantes na feira livre de Lagoa Nova/RN segundo as faixas etárias às quais pertencem.

A idade média observada entre os comerciantes correspondeu a 53,4 anos, com mínimo de 29 e máximo de 82 anos. A faixa etária de maior frequência foi a compreendida entre 21 a 40 anos de idade (Figura 3).

Nossas observações são discordantes com o relato de Alves, Silva e Alves (2008) que relaciona às faixas etárias mais elevadas uma maior participação, afirmando a concentração do conhecimento tradicional entre pessoas de maior idade. Tal discrepância pode ser explicada pelo fato de que na feira livre de Lagoa Nova, nenhum dos comerciantes atuava como curandeiro ou "benzedor", limitando-se a vender o produto e eventualmente, citar suas principais indicações. Possuíam, portanto um conhecimento limitado quanto aos usos e aplicações das plantas medicinais que comercializavam.

A utilização de espécies vegetais em rituais de cura ou "benzeções" é segundo Nogueira, Versonito e Tristão (2012) uma atividade principalmente desenvolvida por mulheres idosas, com pouco ou nenhum grau de instrução, originárias de comunidades rurais e cuja atuação é orientada por preceitos místico-religiosos. Embora os comerciantes e "benzedoras" possuam um perfil socioeconômico de modo geral similar, devemos considerar a existência de uma cisão entre a atividade comercial e os rituais de cura. Desse modo, os indivíduos estudados na feira livre de Lagoa Nova podem ser considerados como simples comerciantes do produto. Tal afirmação é corroborada pelo fato de que em $100,0 \%$ dos casos, os mesmos não efetuavam a identificação nem a coleta das espécies que comercializavam, adquirindo-as a partir de terceiros. Atuavam, portanto, como "atravessadores" (intermediários) entre os coletores originais (raizeiros) - estes sim os reais detentores do conhecimento etnobotânico original - e os usuários das plantas medicinais.

Em relação à raça (cor), 40,0\% dos entrevistados se declararam negros, $20,0 \%$ pardos e 40,0\% brancos (Figura 4), grupos étnicos predominantemente observados por Araújo et al (2009) em estudo desenvolvido na cidade de Maceió/AL. Contudo, contrariamente aos autores citados, não constatamos a presença de índios entre os comerciantes de plantas medicinais de Lagoa Nova/RN. Em ambos os estudos as observações são concordantes com os dados do Censo 2010, no qual a composição étnica da população urbana brasileira é descrita como majoritariamente composta por indivíduos brancos, negros e pardos, consequência dos padrões históricos de 
ocupação territorial (INSTITUTO BRASILEIRO DE GEOGRAFIA E ESTATÍSTICA, 2013a).

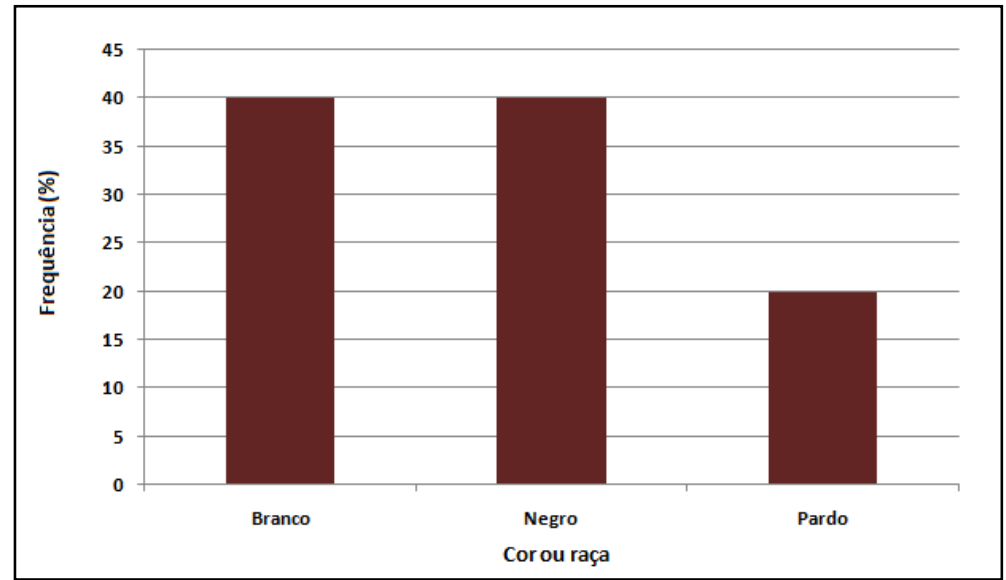

FONTE: Dados do pesquisador.

Figura 4 - Distribuição percentual dos comerciantes de plantas medicinais atuantes na feira livre de Lagoa Nova/RN segundo a sua cor ou raça.

Em relação à Renda Familiar mensal, 80,0\% dos entrevistados relatou valores abaixo de 1 salário mínimo, enquanto $20,0 \%$ a situou na faixa entre 1,1 a 3 salários mínimos (Figura 5). Os mesmos estratos de renda familiar também foram observados por Araújo et al. (2009) em estudo similar desenvolvido na cidade de Maceió/AL. Em todos os casos considerados em nosso estudo, existiam fontes de renda complementares à atividade mercantil. No caso dos comerciantes que se situavam na faixa de renda familiar mensal inferior a um salário mínimo, 75,0\% relatou ser beneficiário de aposentadorias e benefícios concedidos pelo Instituto Nacional do Seguro Social (INSS). Esta constatação é consistente com a idade observada neste caso, entre 57 e 82 anos, com média de 67 anos. Os indivíduos restantes informaram a participação de outros membros da família na composição da renda familiar mensal. Nestes casos, a renda adicional provinha de atividades desenvolvidas no mercado formal de trabalho.

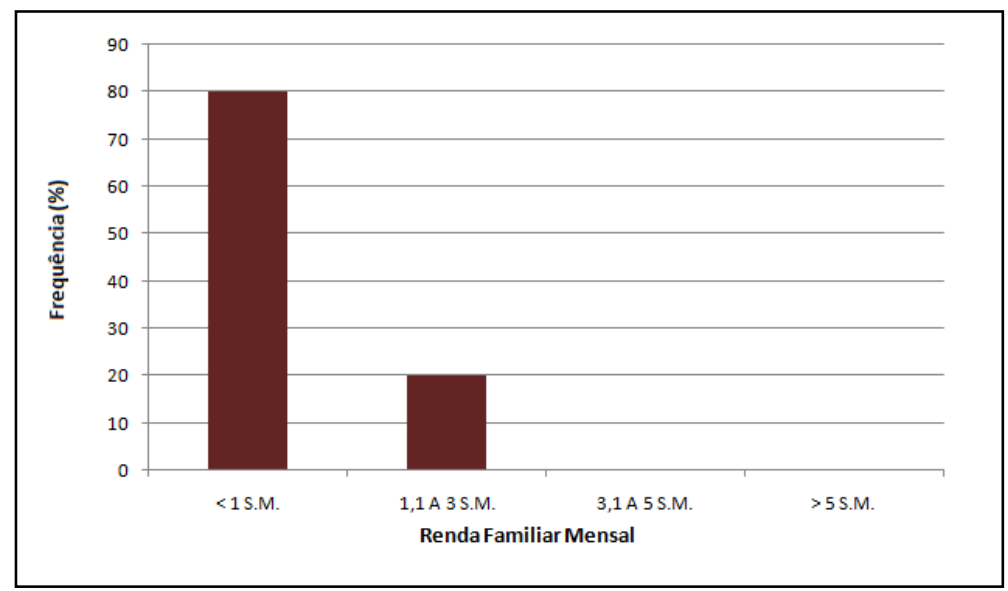

FONTE: Dados do pesquisador.

Figura 5 - Distribuição percentual dos comerciantes de plantas medicinais atuantes na feira livre de Lagoa Nova/RN segundo Renda Familiar Mensal. S.M. = Salário(s) Mínimo(s). 


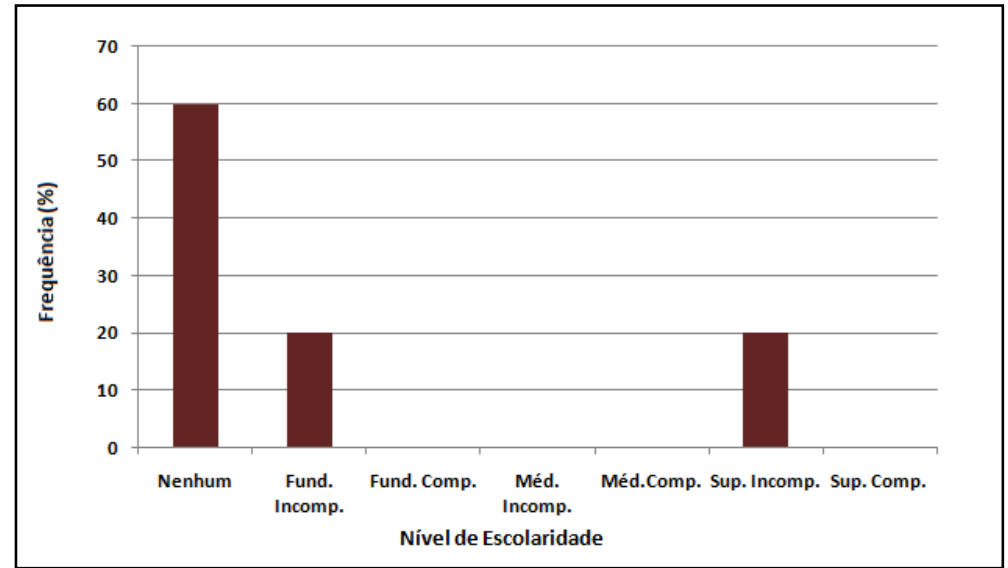

FONTE: Dados do pesquisador.

Figura 6 - Distribuição percentual dos comerciantes de plantas medicinais atuantes na feira livre de Lagoa Nova/RN segundo o nível de escolaridade observado. Fund. Incomp.= Fundamental Incompleto; Fund. Comp. = Fundamental Completo; Méd. Incomp. = Médio Incompleto; Sup. Incomp. = Superior Incompleto; Sup.Comp. = Superior Completo.

Quanto ao nível de escolaridade, $60,0 \%$ relatou não ter concluído nenhum nível de educação formal e $20 \%$ afirmou possuir o nível fundamental incompleto, enquanto outros $20,0 \%$ relatou estar cursando o nível superior (Figura 6). Em estudo desenvolvido em Maceió/AL, Araújo et al. (2009) atestaram a baixa escolaridade dos comerciantes de plantas medicinais sendo que $28,3 \%$ eram analfabetos/semianalfabetos, $19,6 \%$ possuía o ensino médio, enquanto $8,7 \%$ havia concluído o ensino fundamental. Em nosso estudo, portanto, a identificação de indivíduo que afirmou estar cursando o nível superior de educação formal é discrepante em comparação com os relatos de outros pesquisadores.

O cruzamento dos dados relacionados ao nível de escolaridade versus renda familiar declarados, nos permitiu observar que os comerciantes que não possuíam nível de escolaridade ou possuíam apenas o fundamental incompleto, concentravam-se na faixa de renda familiar mais baixa, inferior a 1 salário mínimo por mês. O feirante que declarou possuir o nível superior incompleto por sua vez, situou a sua renda familiar entre 3,1 a 5 salários mínimos. Tal fato abre espaço para investigações posteriores que objetivem determinar se o nível de escolaridade possui alguma influência sobre a arrecadação mensal dos comerciantes de plantas medicinais.

A predominância dos baixos níveis de escolaridade observada pode interferir de forma negativa na qualidade dos produtos disponíveis aos consumidores. Tal afirmação baseia-se no fato de que os conceitos técnicos relacionados à implantação de rotinas de Boas Práticas se fundamentam em instrumentos teórico-metodológicos relativamente complexos, que permitem a compreensão além da percepção sensorial cotidiana (ALMEIDA; PENA, 2011). Desse modo, a baixa escolaridade dificulta ao feirante compreender relações baseadas em conceitos técnicocientíficos abstratos. Neste contexto, por exemplo, torna-se difícil compreender a relação existente entre a contaminação microbiana das plantas medicinais, a veiculação de patógenos no material e o decorrente surgimento de doenças nos usuários.

Em concordância com Alves, Silva e Alves (2008), o baixo grau de escolaridade observado nas feiras livres evidencia a importância econômica da atividade, uma vez que esta oferece uma alternativa viável de geração de renda para pessoas com pouca ou nenhuma instrução formal. Isto se deve ao fato de que a atividade em si, não depende de conhecimentos formais, mas sim dos conhecimentos tradicionais vigentes nos seus grupos sociais de origem. 
Em relação à fonte dos conhecimentos que os entrevistados possuíam acerca dos usos e indicações das plantas medicinais $80,0 \%$ afirmou tê-los recebido no âmbito familiar, enquanto $20,0 \%$, de pessoas conhecidas. Fontes como mídia escrita (livros e jornais) e eletrônica (televisão, internet...) não foram mencionadas por nenhum dos comerciantes (Figura 7). A relevância do ambiente familiar na transmissão de conhecimentos tradicionais também foi ressaltada por Araújo et al. (2009), que em seu estudo realizado em Maceió/AL, registraram que em 56,54\% dos casos a transmissão do conhecimento etnobotânico se deu através de informações fornecidas por pais ou avós. No mesmo estudo, a participação da mídia impressa (livros, revistas) foi de apenas 6,5\%, não ocorrendo relato acerca da influência das demais fontes consideradas em nosso estudo. Lima, Magalhães e Santos (2011), também constataram na cidade de Vilhena/RO a predominância da transmissão oral de tais conhecimentos no âmbito familiar. Portanto, podemos inferir que, apesar da grande penetração das mídias impressa e eletrônica junto à população, as mesmas ainda não possuem influência significativa sobre a transmissão do conhecimento etnobotânico entre os comerciantes de plantas medicinais estudados, o que evidencia o caráter fortemente tradicional da atividade.

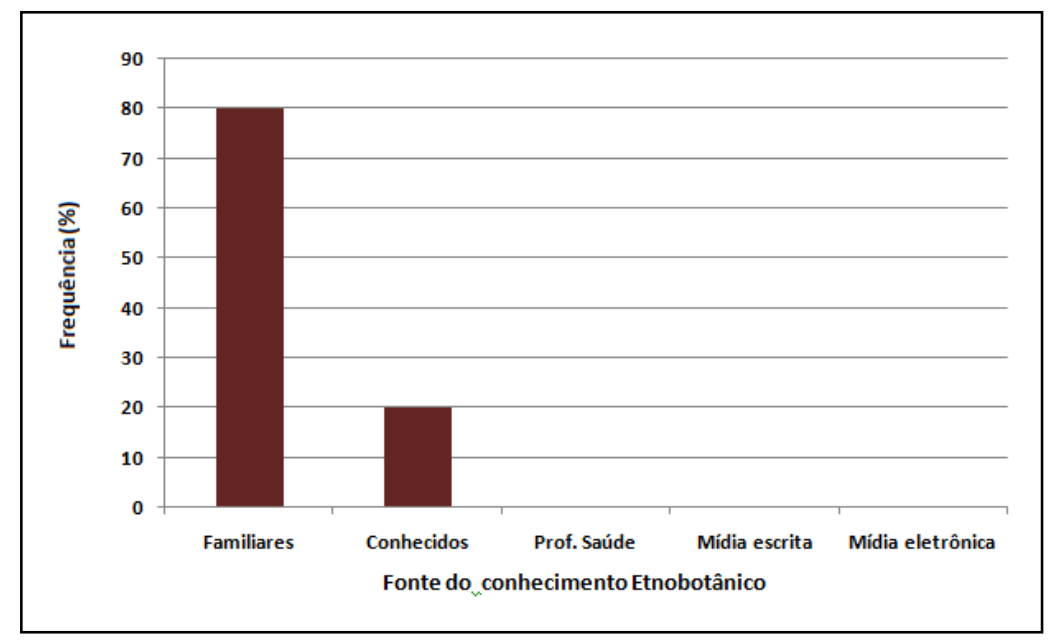

FONTE: Dados do pesquisador.

Figura 7 - Distribuição percentual dos comerciantes de plantas medicinais atuantes na feira livre de Lagoa Nova/RN segundo a fonte a partir da qual obtiveram os conhecimentos etnobotânicos que possuíam. Familiares = transmissão oral no âmbito familiar; Conhecidos = transmissão oral através do contato com pessoas conhecidas; Prof. Saúde = Profissionais da Saúde (médicos, enfermeiros...); Mídia escrita (jornais, revistas, livros...); Mídia eletrônica (televisão, rádio, internet...).

Sessenta por cento dos entrevistados afirmou ter herdado o negócio de pais ou avós (Figura 8). 


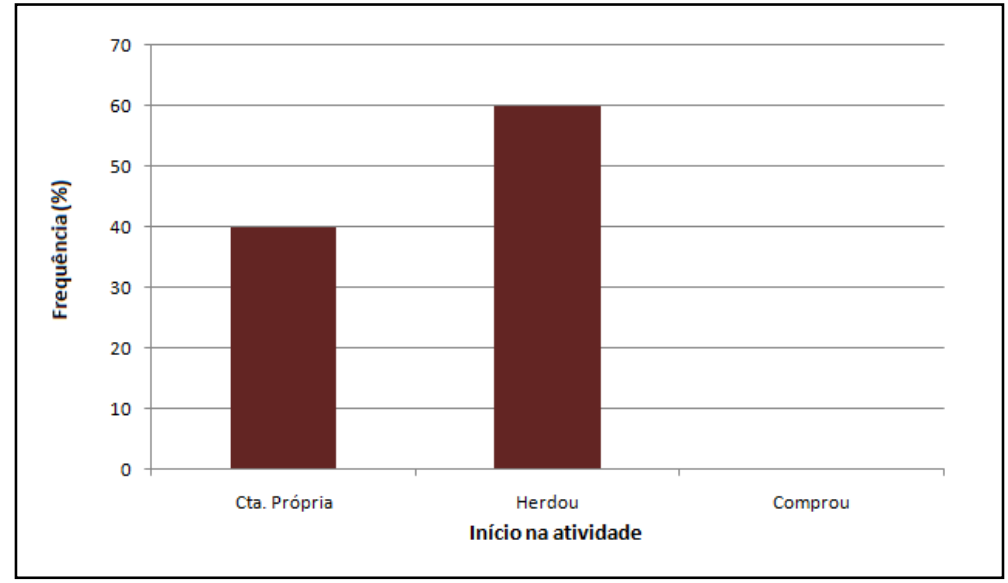

FONTE: Dados do pesquisador.

Figura 8 - Distribuição percentual dos comerciantes de plantas medicinais atuantes na feira livre de Lagoa Nova/RN segundo a forma pela qual iniciaram a sua atividade comercial. Cta. Própria = iniciou o ponto comercial por conta própria; Herdou = herdou o ponto comercial de familiares; Comprou = adquiriu o ponto comercial a partir de terceiros.

Tal observação reflete o caráter familiar da comercialização de plantas medicinais na feira livre estudada. Oitenta por cento dos comerciantes que declararam ter herdado o ponto de venda, afirmou que os seus descendentes (filhos e/ou netos) permaneceriam no ramo, demonstrando uma tendência à continuidade da família na venda de plantas medicinais na feira livre de Lagoa Nova. Tal fato contrasta com as observações de Araujo et al. (2009), nas quais se evidencia a preocupação com o desinteresse das novas gerações em continuar atuando no ramo, o que teria como possível consequência, o seu desaparecimento nas feiras livres ao longo do território nacional.

A intenção das novas gerações em dar continuidade à tradição familiar na venda de plantas medicinais em Lagoa Nova deve ser encarada como positiva, já que é fonte potencial de informações relevantes à prospecção de novos fármacos e acerca dos usos e sustentabilidade na exploração da caatinga. Adicionalmente, devemos considerar o impacto econômico positivo que exerce sobre o orçamento das famílias de baixa renda. Nestes casos, os recursos da medicina tradicional constituem uma fonte alternativa de baixo custo aos fármacos sintéticos utilizados no tratamento de suas doenças (ALVES; SILVA; ALVES, 2008).

Todos os pontos de comercialização visitados possuíam estrutura temporária constituída por suportes metálicos aos quais se encaixavam tampos de madeira, formando balcões improvisados sobre os quais as plantas eram expostas. O material disponível estava acondicionado na maioria dos casos, em sacos de material plástico (ráfia) reutilizados. Abertos e sem proteção, permitiam o livre acesso de poeiras e insetos (Figura 9). 


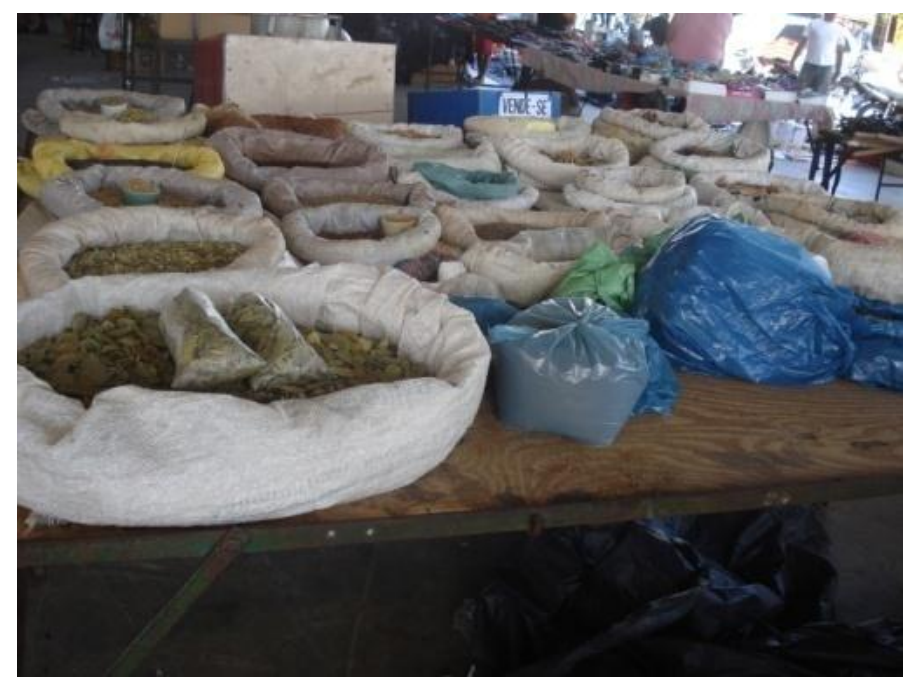

FONTE: Arquivo do pesquisador.

Figura 9 - Forma típica de exposição das plantas medicinais comercializadas na feira livre de Lagoa Nova.

Antes e após o funcionamento da feira, as plantas eram mantidas em caixotes de madeira, nos mesmos sacos e recipientes utilizados para a sua exposição. Todos os entrevistados afirmaram efetuar o armazenamento em sacos plásticos, embora tenha sido observado em um caso o uso de recipientes plásticos reutilizados (Figuras 10 e 11).

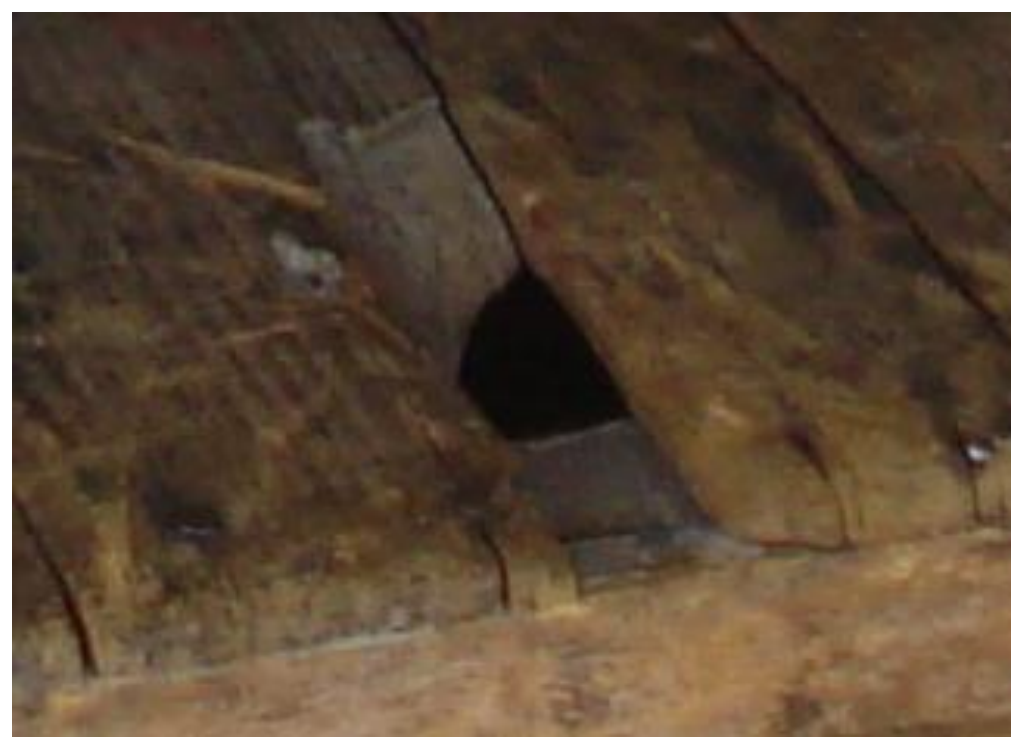

FONTE: Arquivo do pesquisador.

Figura 10 - Detalhe da tampa protetora danificada de caixote de madeira utilizado no armazenamento e transporte das plantas medicinais comercializadas na feira livre de Lagoa Nova. 


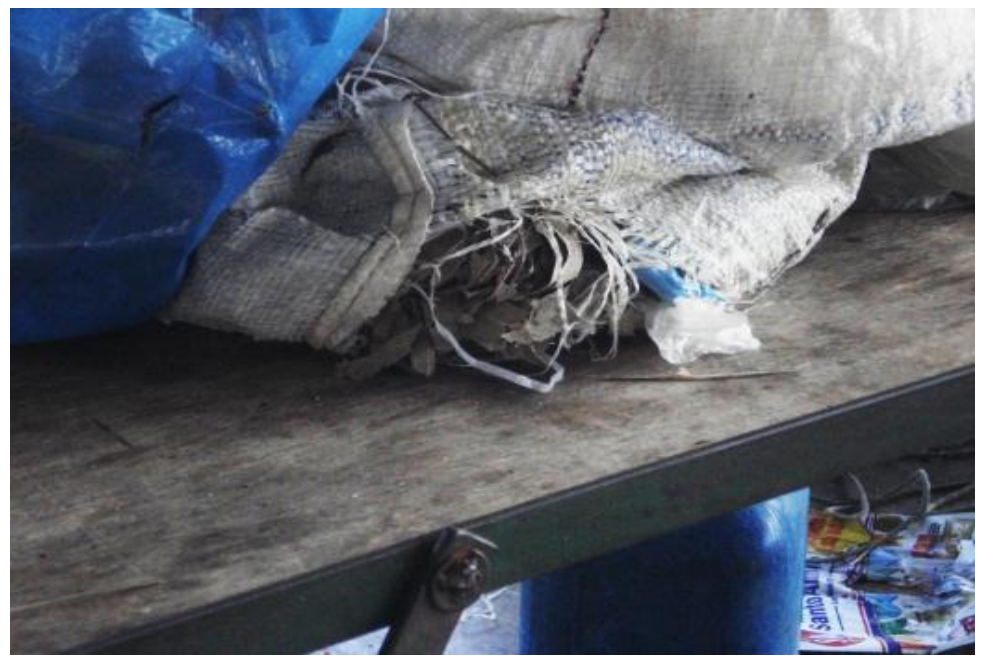

FONTE: Arquivo do Pesquisador.

Figura 11 - Detalhe de um dos sacos utilizado para a exposição e armazenamento de plantas medicinais dessecadas em um dos pontos de comercialização estudados na feira livre de Lagoa Nova/RN.

A inadequação higiênico-sanitária da estrutura física e das práticas de comercialização/armazenamento observadas in loco, são favoráveis à introdução e proliferação de microbiota indesejável nos produtos disponíveis. A contaminação de plantas medicinais por fungos e bactérias patogênicos tem sido relatada mundialmente e é reconhecida pela Organização Mundial da Saúde como um problema de saúde pública (WORLD HEALTH ORGANIZATION, 2007). Dentre as consequências potenciais relacionadas à presença de microbiota deteriorante e/ou patogênica nas plantas medicinais estão a perda de seus princípios ativos e a promoção de infecções/intoxicações no usuário final (AMARAL et al., 2003; MEDEIROS et al., 2012; STEVIC et al., 2012; ROCHA et al., 2010; WORLD HEALTH ORGANIZATION, 2007; ZANG et al., 2012).

No contexto da verificação da qualidade e conservação dos seus estoques de plantas medicinais, $80,0 \%$ dos entrevistados relatou efetuar a verificação ao menos uma vez na semana, enquanto $20,0 \%$ ao menos uma vez ao mês. A alta frequência de verificação declarada pelos comerciantes pode refletir menos da preocupação com a qualidade e conservação dos produtos e mais da necessidade de montar e desmontar a estrutura dos seus pontos de venda semanalmente.

Em relação ao tempo de estocagem das plantas medicinais (Figura 12), apenas 20,0\% declarou manter um mesmo lote pelo período máximo de até 2 meses. Outros 20,0\% o fazia por até 3 meses. A manutenção de estoques por período superior a 3 meses foi relatada em $60,0 \%$ dos casos. Um dos entrevistados ressaltou que mantinha o lote adquirido "até vender tudo". Segundo Matos (1998), as plantas medicinais não devem permanecer em estoque por períodos superiores a 3 meses, mesmo sob condições de armazenagem adequadas, diversas daquelas observadas na feira livre de Lagoa Nova/RN. 


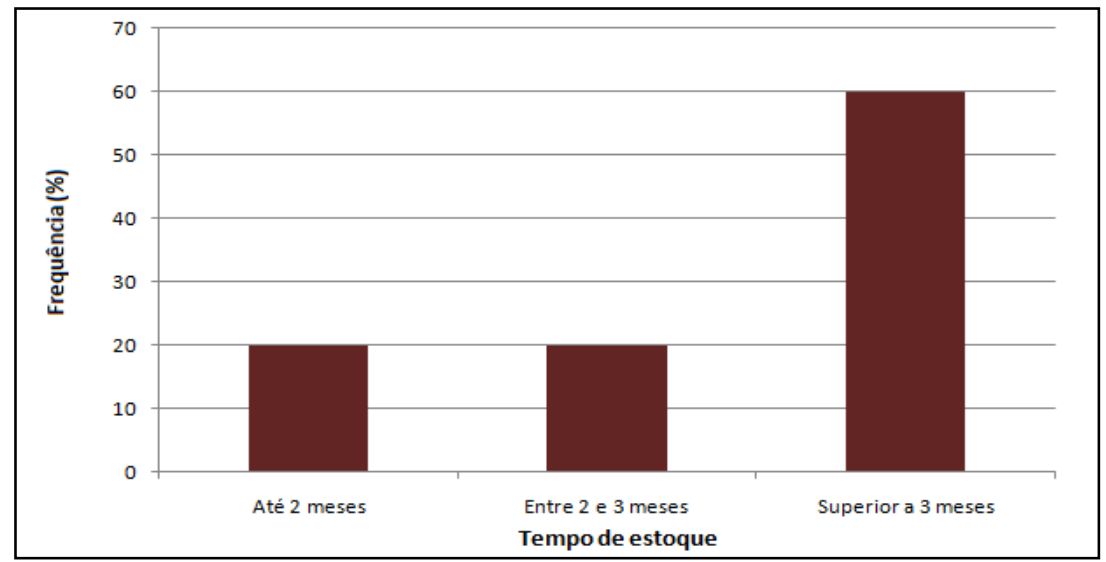

FONTE: Arquivo do Pesquisador.

Figura 12 - Distribuição percentual dos comerciantes de plantas medicinais atuantes na feira livre de Lagoa Nova/RN segundo o tempo que consideravam adequado à manutenção das plantas medicinais em estoque, sem perda de sua qualidade.

Deve-se ter em mente que a ação terapêutica de uma planta medicinal advém de um ou mais princípios ativos presentes entre as centenas de substancias originárias do seu metabolismo primário ou secundário, componentes do que é conhecido como fitocomplexo (BRASIL, 2010). Imediatamente após a colheita inicia-se a alteração química do fitocomplexo, resultado de hidrólises, exposição excessiva a luz ou ao calor, oxidação ou através do metabolismo de contaminantes microbianos (SILVA et al., 1999). Tais alterações podem resultar na diminuição ou perda da(s) atividade(s) terapêutica(s) esperada(s), toxicidade e/ou reações adversas nos usuários.

Embora nossas observações denunciem o armazenamento por tempo superior ao recomendado para a manutenção da qualidade e eficácia das plantas medicinais, 80,0\% dos entrevistados reconheceu que, de modo similar às drogas sintéticas, as plantas medicinais também perdem sua eficiência terapêutica, declarando acreditarem em um "prazo de validade" (Figura 13). Registra-se, portanto, uma flagrante discrepância entre o que os comerciantes declararam acreditar e a prática vigente em seu ponto de comercialização, com prejuízo potencial à qualidade, segurança e eficácia terapêutica dos produtos disponíveis.

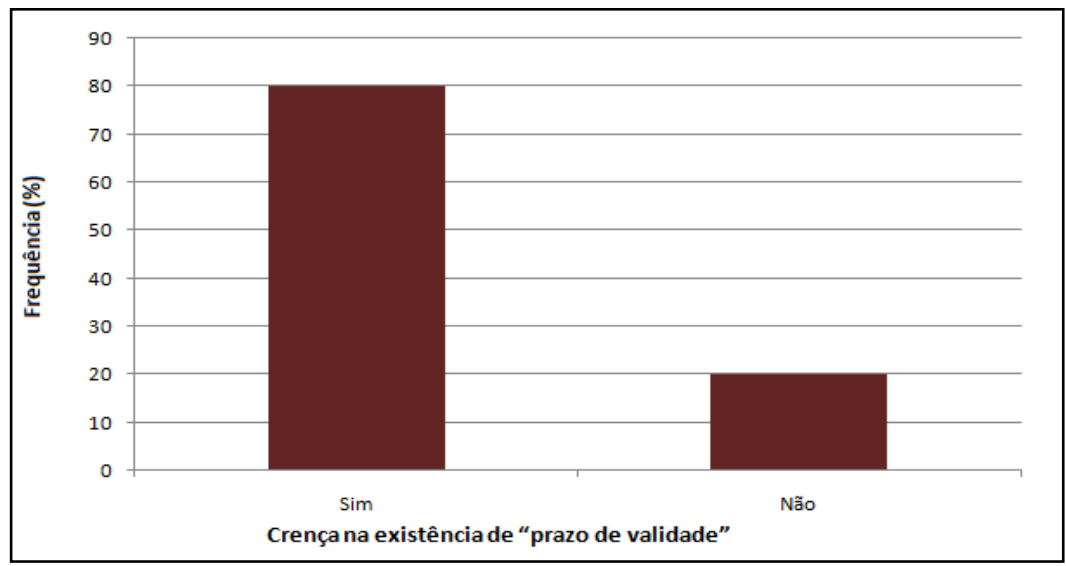

FONTE: Arquivo do Pesquisador.

Figura 13 - Distribuição percentual dos comerciantes de plantas medicinais atuantes na feira livre de Lagoa Nova/RN segundo sua crença na existência de "prazo de validade" para as plantas medicinais que comercializa. 
Em comparação com as drogas sintéticas, $100,0 \%$ dos comerciantes afirmaram que as plantas que vendiam eram "melhores" e mais seguras, não comercializando nenhuma espécie que pudesse representar risco ao usuário. Tais crenças não refletem a verdade, uma vez que a ação benéfica ou a toxicidade de uma dada espécie vegetal associa-se à presença e à concentração de uma ou mais substâncias em seu fitocomplexo. Contudo, a concentração de fitoquímicos é muito variável, em dependência de fatores intrínsecos e extrínsecos à própria planta. Uma mesma espécie pode apresentar ação terapêutica em uma dada concentração e tóxica quando em dosagens mais elevadas (FUNGH-BERMAN, 2000). Adicionalmente, plantas medicinais comumente encontradas nas feiras livres nordestinas como a cabacinha (Luffa operculata (L.) Congn.) e a babosa (Aloe vera (L.) Burm. f.) são listadas na Poisonous Plant Database como espécies tóxicas (ROCHA, 2009; U.S. FOOD AND DRUG ADMINISTRATION, 2012).

Dentre os entrevistados, $80,0 \%$ acreditavam que os "remédios de farmácia" (drogas alopáticas) poderiam ser utilizados em conjunto com as plantas medicinais ou produtos produzidos a partir destas (Figura 14). Embora a associação entre plantas medicinais e medicamentos sintéticos nem sempre resulte em alterações indesejáveis clinicamente relevantes, este potencial não deve ser desprezado. Considerando o fitocomplexo, podemos pressupor interações potenciais. Tais associações podem resultar em alterações farmacocinéticas (relativas à absorção, distribuição, metabolismo e excreção das drogas) ou farmacodinâmicas (relacionadas aos efeitos farmacológicos combinados das drogas e fitocomplexo), alterando a efetividade e/ou a segurança do medicamento. Espécies comuns nas feiras livres como alho (Allium sativum L.), camomila (Matricaria recutita L.) e boldo (Peumus boldus Molina) podem potencialmente interagir com drogas antihipertensivas, anticoagulantes, hipoglicemiantes e depressoras do SNC, com risco de potencialização dos seus efeitos. O quebra-pedras (Phyllanthus niruri L.) por sua vez, pode potencializar a ação de diuréticos e antihipertensivos. $P$. niruri pode também aumentar os efeitos tóxicos do Lítio, quando associada às drogas que contenham tal elemento (BARNES et al, 2003; CAPASSO et al.,2000; KUHN, 2002; ROCHA, 2009).

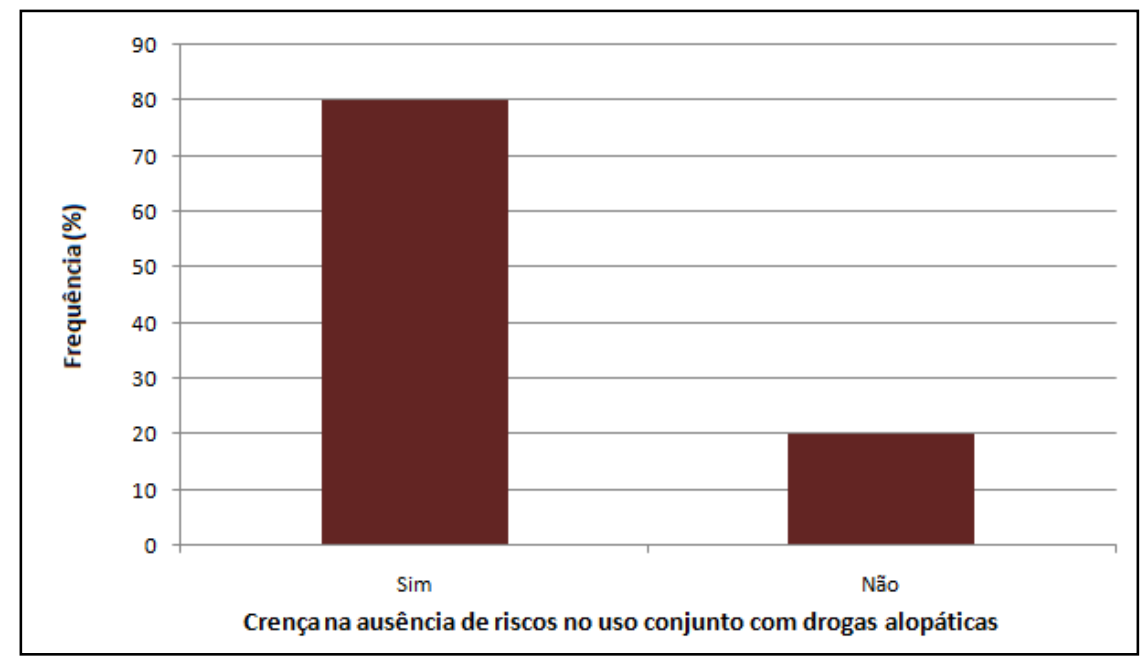

FONTE: Dados do pesquisador.

Figura 14 - Distribuição percentual dos comerciantes de plantas medicinais atuantes na feira livre de Lagoa Nova/RN segundo sua crença na existência de riscos no uso contemporâneo de plantas medicinais e drogas alopáticas. 
Todos os entrevistados afirmaram que as plantas medicinais que comercializavam poderiam ser associadas entre si, não resultando em alterações indesejáveis na qualidade e segurança do tratamento. Contudo, assim como as drogas sintéticas, as espécies vegetais bioativas podem interagir entre si. Como resultado, a intensidade de uma dada ação biológica pode ser afetada em dependência do tipo de interação ocorrida entre compostos presentes em seus fitocomplexos. Interações dos tipos adição, sinergismo e potenciação resultam em aumento do efeito. Já as classificadas como antagônicas, promovem a sua redução.

Diante do risco potencial de interações indesejáveis entre fitoquímicos, devemos considerar o consumo dos denominados "preparos tradicionais" comuns na medicina tradicional nordestina. Tais produtos são extratos de base alcoólica, aquosa ou xaropes à base de açúcar, nos quais estão associadas diversas plantas medicinais. Tradicionalmente, tais produtos são denominados "lambedores", "garrafadas" e "tinturas", sendo amplamente aceitos pelas populações locais. Seu consumo, quando respaldado pela utilização tradicional há décadas é, de modo geral, relativamente seguro. Contudo, com a massificação do conceito distorcido de que "o que é natural não faz mal" e a comercialização por pessoas que não detêm o conhecimento etnobotânico original, existe o risco de adulteração das formulas com a inclusão uma ou mais espécies vegetais não indicadas. Tais modificações podem gerar as interações anteriormente discutidas, afetando a segurança e a eficácia do tratamento, resultando em risco à saúde do usuário (CAPASSO et al., 2000; ROCHA, 2007; ROCHA, 2009).

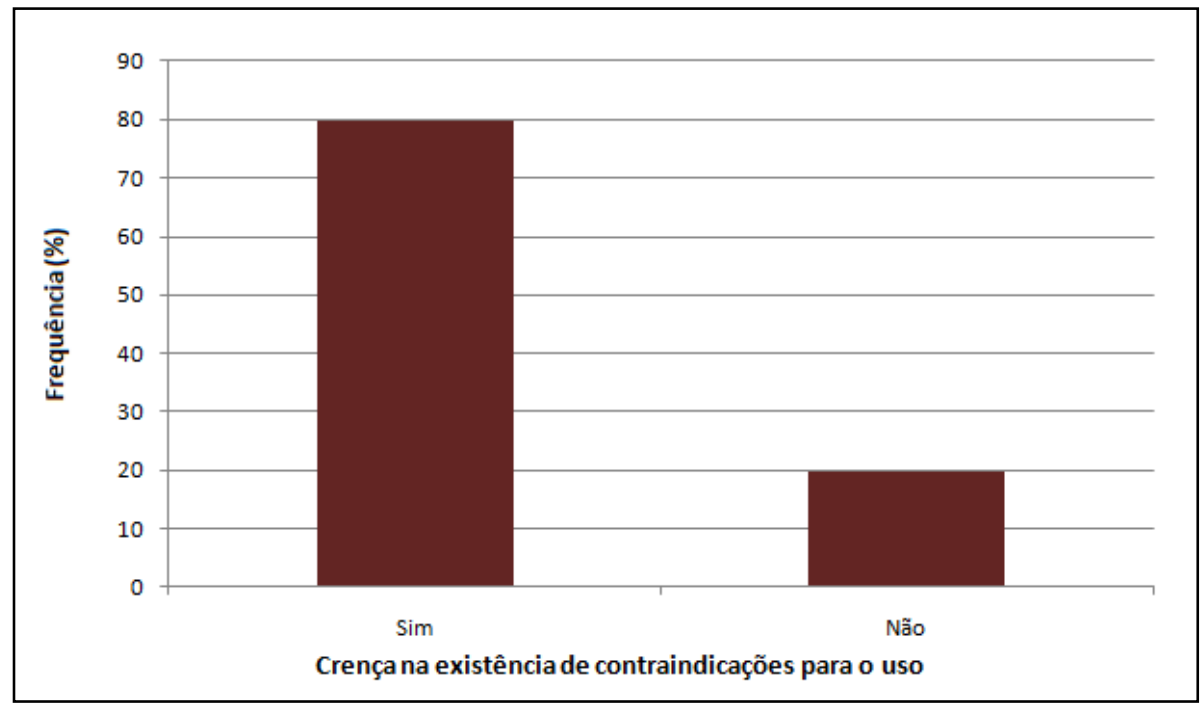

FONTE: Dados do pesquisador.

Figura 15 - Distribuição percentual dos comerciantes de plantas medicinais atuantes na feira livre de Lagoa Nova/RN segundo sua crença na existência de "contraindicações" para o uso das plantas medicinais que comercializa.

Oitenta por cento dos entrevistados afirmaram acreditar que de forma similar aos medicamentos alopáticos, as plantas medicinais apresentam contraindicações para o seu uso. Contudo, em $100,0 \%$ dos casos foram incapazes de exemplificar, mesmo quando consideradas apenas as espécies vegetais que comercializavam (Figura 15).

Em nenhum dos casos, a gravidez foi citada como um estado no qual o uso de plantas medicinais deve ser cauteloso. Tal observação é preocupante, dado o potencial abortivo de 
espécies comumente utilizadas pela população para o preparo de chás, tais como Rosmarinus officinalis L. (alecrim), P. boldus Molina (boldo do chile) e M. recutita L. (camomila), dentre outras (RIO DE JANEIRO, 2002).

\section{CONCLUSÃO}

A comercialização de plantas medicinais no município de Lagoa Nova/RN é predominantemente uma atividade desenvolvida por homens negros e brancos, de baixa renda familiar e baixo nível de escolaridade. A transmissão do conhecimento etnobotânico foi predominantemente realizada no âmbito familiar, sendo que $60 \%$ dos comerciantes herdaram o ponto de venda de avós ou pais, sendo que seus filhos e/ou netos continuarão na atividade.

As condições estruturais observadas, bem como as práticas empregadas no armazenamento e comercialização eram precárias, favorecendo a contaminação e a baixa qualidade do produto. Observou-se entre os entrevistados o desconhecimento dos riscos à saúde humana, representados pelo uso inadequado das plantas medicinais, seja pela sua contaminação microbiana, descontextualização cultural, associação entre ervas e drogas alopáticas ou mesmo da toxicidade das espécies que comercializavam.

Torna-se necessário o desenvolvimento de atividades que visem à implantação de rotinas de Boas Práticas junto aos comerciantes, esclarecendo-os acerca dos riscos à saúde humana decorrentes do comércio inadequado e do uso indiscriminado das plantas medicinais. É urgente que seja criado no país, aparato legal específico, voltado ao estabelecimento de parâmetros de qualidade e de conduta adequados para a comercialização em feiras livres de plantas medicinais brutas e preparos tradicionais, de modo a reduzir o impacto negativo sobre a saúde dos usuários.

\section{REFERÊNCIAS BIBLIOGRÁFICAS}

1. ALMEIDA, M. D.; PENA, P. G. L. Feira livre e risco de contaminação alimentar: estudo de abordagem etnográfica em Santo Amaro, Bahia. Revista Bahiana de Saúde Pública. v. 35, n. 1, p. 112, 2011.

2. AMARAL, F. M. M.; COUTINHO, D. F.; RIBEIRO, M. N. S.; OliVEIRA, M. A. Avaliação da qualidade de drogas vegetais comercializadas em São Luiz/Maranhão. Revista Brasileira de Farmacognosia. v.3 sup. 1, 2003.

3. ARAÚJO, A.C. et al. Caracterização socioeconômico-cultural de raizeiros e procedimentos pós-colheita de plantas medicinais comercializadas em Maceió, AL. Revista Brasileira de Plantas Medicinais. v. 11, n. 1, p. 81-91, 2009.

4. ALVES, R.N.A.; ALVES, R.N. A.; SILVA, A.A.G.; SOUTO, W. M.S.; BARBOZA, R.R.D.; DOURADO, E.R.; DOCA, K.N.P., ARAÚJO, T.C.C. Levantamento etnobotânico de plantas medicinais. Revista Brasileira de Farmácia. Viçosa-MG, p.316-320, 2009.

5. ALVES, R. R. N.; SILVA, C. C.; ALVES, H. N. Aspectos sócioeconômicos do comércio de plantas e animais medicinais em áreas metropolitanas do Norte e Nordeste do Brasil. Revista de Biologia e Ciências da Terra. Ano 1, v. 1, n. 1, 2008.

6. ASSOCIAÇÃO BRASILEIRA DAS EMPRESAS DO SETOR DE FITOTERÁPICOS, SUPLEMENTO ALIMENTAR E DE PROMOÇÃO DA SAÚDE. Comércio formal e perfil de consumidores de 
plantas medicinais e fitoterápicos no município de Itaqui. Rev. Bras. Pl. Med., Botucatu, v.13, n.2, p.121-128, 2011.

7. BRASIL. Distrito Federal. Lei $n^{\circ} 1828$, de13 de janeiro de 1998. Disciplina a organização e o funcionamento das feiras livres e permanentes no Distrito Federal. Diário Oficial da União, 13/01/1998.

8. BRASIL. MINISTÉRIO DAS MINAS E ENERGIA. Projeto de fontes de abastecimento por água subterrânea no Estado do Rio Grande do Norte: Diagnóstico do Município de Lagoa Nova. Brasília, DF, 2005.

9. BRASIL. MINISTÉRIO DA SAÚDE. AGENCIA NACIONAL DE VIGILÂNCIA SANITÁRIA. RDC n¹4 de 31 de março de 2010. Dispõe sobre o registro de medicamentos fitoterápicos. Diário Oficial da União, n. 63, 5 de abril de 2010.

10. BRASIL. MINISTÉRIO DA FAZENDA. Decreto $\mathrm{n}^{\circ} 755$ de23 de dezembro de 2011. Regulamenta a Lei no 12.382, de 25 de fevereiro de 2011, que dispõe sobre o valor do salário mínimo e a sua política de valorização de longo prazo. Diário Oficial da União. Poder Executivo, Brasília, DF, 26 dez 2011. N. 247, seção 1, p. 5.

11. CAPASSO, R.; IZZO, A.A.; PINTO, L; BIFULCO, T,; VITOBELLO, C.; MASCOLO,N.Phytotherapy and quality of herbal medicines. Fitoterapia. n. 71, p. 58, 2000.

12. FERREIRA, Sérgio Henrique. Medicamentos a partir de plantas medicinais no Brasil. Fitoterapia, n 52, 2002.

13. FUNGH-BERMAN,A. Herb-Drug interactions. Lancet, n. 35, p. 134-38, jan. 2000.

14. INSTITUTO BRASILEIRO DE GEOGRAFIA E ESTATÍSTICA. (2013a). Sinopse do Censo Demográfico 2010: Rio Grande do Norte. IBGE. Disponível em:<http://www.censo2010.ibge.gov.br/sinopse/index.php?uf=24\&dados=1. Acesso em: 1 jun. 2013.

15. INSTITUTO BRASILEIRO DE GEOGRAFIA E ESTATÍSTICA. (2013b). Mapas escolares. IBGE. Disponível em: <http://mapas.ibge.gov.br/escolares>. Acesso em 15 fev 2013.

16. KUHN, M. A. Herbal remedies: drug-herb interactions. Critical Care Nurse. v.22, n. 2, abr 2002.

17. LIMA, R. A.; MAGALHÃES, S. A.; SANTOS, M. R. A. Levantamento Etnobotânico de plantas medicinais utilizadas na cidade de Vilhena, Rondônia. Revista Pesquisa \& Criação. v. 10, n. 2, p. 165-179, 2011.

18. LORENZI, H.; MATOS, F.J.A. Perfil dos raizeiros e estudos de suas indicações. Revista de Biologia e Farmácia - Biofar. v.3, n.1, p. 102-109, 2008.

19. MATOS, F. J. A. Farmácias Vivas: sistema de utilização de plantas medicinais projetado para pequenas comunidades. 3 ed. Fortaleza: EUFC, 1998.

20. MELO, J.G. Comércio formal e perfil de consumidores de plantas medicinais e fitoterápicos no município de Itaqui. Revista Brasileira de Plantas Medicinais. v.13, n.2, p.121-128, 2011.

21. MEDEIROS, F.G.M; ROCHA, F.A.G.; MEDEIROS, U.K.L.; DANTAS, L.I.S.; ARAÚJO, L.O.; ARAÚJO, M.F.F. Comparação da qualidade sanitária de amostras de Peumus boldus Molina industrializadas e artesanais do município de Currais Novos, RN. Holos. 3, 41-46, 2012. 
22. MinNAERT, A. C. S. T.; FREITAS, M. C. S. Práticas de higiene em uma feira livre da cidade de Salvador (BA). Ciência \& Saúde Coletiva. n. 15, p. 1607-1614, 2010.

23. NOGUEIRA, L. C.; VERSONITO, S. M.; TRISTÃO, B. D. O dom de benzer: a sobrevivência dos rituais de benzeção nas sociedades urbanas - o caso do município de Mara Rosa, Goiás, Brasil. Elisée - Revista de Geografia da UEG. v.1, n.1 2, p. 167-181, 2012.

24. RIO DE JANEIRO (ESTADO). Reslução SES/RJ n 1757 de 18 de fevereiro de 2002. Contra-indica o uso de plantas medicinais no âmbito do estado do Rio de Janeiro. Diário Oficial do Estado do Rio de Janeiro. Ano 27, n. 33, Parte I, 20 fev. 2002.

25. ROCHA, Francisco Angelo Gurgel da. Uso de Plantas medicinais: fonte de riscos à saúde humana?. Dissertação (Mestrado em Desenvolvimento e Meio Ambiente). PRODEMA - UERN, 2007.

26. ROCHA, F. A. G. Plantas medicinais: um perfil etnofarmacológico. 1 ed. 248 p. Natal: Editora do IFRN, 2009.

27. ROCHA, F. A. G.; MEDEIROS, F. G. M.; SILVA, J. L. A. Diagnóstico da qualidade sanitária de plantas medicinais comercializadas no município de Currais Novos, RN. HOLOS, ano 26, v. 2. 2010.

28. ROCHA, C. H et al. Perfil socioeconômico dos feirantes e consumidores da feira do produtor de Passo Fundo, RS. Ciência Rural. v. 40, n.12 p. 2593-2597, 2010.

29. RODRIGUES, A.C.C.; GUEDES, M.L.S. Caracterização socioeconômica. Revista Brasileira de Plantas Medicinais. v.11, n.1, p.81-91, 2009.

30. CHOLZ, C. Perfil dos raizeiros e estudos de suas indicações. Revista de Biologia e Farmácia Biofar. v.3, n.1, p. 102-109, 2008.

31. CHVARTSMAN, S. Uso popular de plantas medicinais. Saúde \& Ambiente em Revista, Duque de Caxias-RJ, v.1, n.2, p.76-85, jul-dez 2006.

32. SILVA, F.; CASALI, V. W. D.; LIMA, R. R.; ANDRADE N. J. Qualidade pós-colheita de Achillea millefolium L.,Origanum vulgare L. e Petroselinum crispum A. W. Hill em três embalagens. Revista Brasileira de Plantas Medicinais. v. 2, n. 1, p. 37-41, 1999.

33. STATSOFT, Inc. STATISTICA (Data Analysis Software System), version10. www.statsoft.com. 2010.

34. STEVIC, T.; et al. Pathogenic microorganisms of medicinal herbal drugs. Archives of Biological Science. v.64, n. 1, 49-58, 2012.

35. U.S. FOOD AND DRUG ADMINISTRATION. FDA Poisonous Plant Database. Base de dados. 2012.

Disponível em:<http://www.accessdata.fda.gov/scripts/plantox/textResults.cfm>.Acesso em 08 jul. 2012.

36. WORLD HEALTH ORGANIZATION. WHO guidelines for assessing quality of herbal medicines with reference to contaminants and residues. Geneva: WHO Press, 2007.

37. ZANG, J.; W. B.; SHANG, H.; Li, X. Quality of herbal medicines: challenges and solutions. Complementary Therapies in Medicine. v. 20, n. 1, p. 100-106, 2012. 